\title{
Effects of Melatonin on Ischemia-Reperfusion Injury in Rat Ovary: Histopathologic and Immunohistochemical Study
}

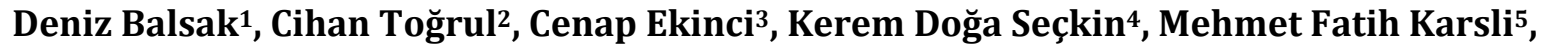 \\ Aysun Ekinci', Ali Emre Tahaoğlu7, Hanefi Bademkiran' ${ }^{8}$, Zuat Acar', Senem Yaman Tunç'10, \\ Engin Deveci ${ }^{3 *}$, Günsen Kirman ${ }^{3}$ \\ ${ }^{1}$ Department of Obstetrics and Gynecology, School of Medicine Hospital, University of Haliç, Istanbul, Turkey \\ ${ }^{2}$ Department of Obstetrics and Gynecology, School of Medicine, University of Hitit, Çorum, Turkey \\ ${ }^{3}$ Department of Histology and Embryology, School of Medicine Hospital, University of Dicle, Diyarbakir, Turkey \\ ${ }^{4}$ Department of Obstetrics and Gynecology, Kanuni Sultan Süleyman, Education and Research Hospital, \\ Istanbul, Turkey \\ ${ }^{5}$ Department of Obstetrics and Gynecology, Dr. Sami Ulus, Education and Research Hospital, Ankara, Turkey \\ ${ }^{6}$ Department of Biochemistry, Faculty of Medicine, University of Dicle, Diyarbakir, Turkey \\ ${ }^{7}$ Department of Obstetrics and Gynecology, Diyarbakir Gazi Yaşargil Education and Research Hospital, \\ Diyarbakir, Turkey \\ ${ }^{8}$ Department of Obstetrics and Gynecology, Diyarbakir Obstetrics and Gynecology Hospital, Diyarbakir, Turkey \\ ${ }^{9}$ Department of Obstetrics and Gynecology, Memory Hospital, Diyarbakir, Turkey \\ ${ }^{10}$ Department of Obstetrics and Gynecology, School of Medicine Hospital, University of Dicle, Diyarbakir, Turkey \\ Email: engindeveci64@gmail.com
}

Received 28 July 2015; accepted 21 September 2015; published 24 September 2015

Copyright $(2015$ by authors and Scientific Research Publishing Inc.

This work is licensed under the Creative Commons Attribution International License (CC BY).

http://creativecommons.org/licenses/by/4.0/

(c) (i) Open Access

\section{Abstract}

Aim: To investigate the effect of melatonin on ischemia-reperfusion (I/R) injury in rat ovary. Material and Method: A total of 24 Wistar rats were divided into four groups. The rats were first numbered randomly and then randomly divided into four equal groups: sham, torsion, detorsion and melatonin groups. In group I $(n=6)$ sham, as well as in group II ovary torsion was not performed and no drug was administered. In group III, 1 hour of ischemia and 2 hours of reperfusion were performed and no drug was given. In group IV, melatonin was dissolved in $1 \%$ ethanol just before use. Melatonin was injected 1 hour before torsion to the torsion plus melatonin group. Right ovaries were surgically removed in all groups. Result: Malondialdehyde (MDA) levels were measured. We suggested that administration of melatonin would be in treating ovaries from torsion/detorsion induced damage in humans. The histopathological changes such as vascular con-

*Corresponding author.

How to cite this paper: Balsak, D., et al. (2015) Effects of Melatonin on Ischemia-Reperfusion Injury in Rat Ovary: Histopathologic and Immunohistochemical Study. Open Journal of Obstetrics and Gynecology, 5, 639-645.

http://dx.doi.org/10.4236/ojog.2015.511090 
gestion, edema, hemorrhage, and follicular degeneration were found to be decreased in the melatonin + ischemia-reperfusion group. Ischemia-reperfusion group: PECAM-I expression is positive in vessel of the stromal area. The follicles and interfolicular area infiltrated with $C D 68$ positive cells were increased in a time of ischemia-reperfusion exposure dependent manner. Conclusions: Melatonin after ischemia-reperfusion CD31 and CD68 expressions is weak, due to the reduction of the inflammatory effects and hemorrhage is thought that melatonin is effective.

\section{Keywords}

Ischemia-Reperfusion, Ovary, Rat, CD31, CD68

\section{Introduction}

Ovarian ischemia is the result of torsion and leads to cell death because of insufficient perfusion of the tissue [1] [2]. Ischemic tissues need to recover blood supply for regeneration of cells reperfusion of the ischemic tissue, leading to more serious damage to the tissue than the damage caused by ischemia [3]. Maintaining the circulation of the ovary after detorsion worsens the tissue injury and leads to a pathologic process called ischaemia/reperfusion [4]. During adnexal (ovary, tube, or both) torsion, venous flow is the first to be impaired, followed by the compromised arterial blood flow [5]. Complete arterial obstruction does not usually occur [6]. This pathophysiology leads to congestion, adnexal edema, discoloration, ischemia, and necrosis. Melatonin is a free radical scavenger antioxidant which protects cells against the damage induced by several oxidative agents [7] [8]. CD31 antigen (PECAM-1) is a single chain transmembrane glycoprotein with a molecular weight of 130 to $140 \mathrm{kD}$. The CD31 molecule is expressed on the surface of platelets, monocytes, and granulocytes. The properties of CD31 antigen suggest that it is involved in interactive events during angiogenesis, thrombosis and wound healing [9]. Macrophages are major secretory cells capable of releasing cytokines, chemokines and growth factors that function in normal, inflammatory and disease processes of most tissues [10]. CD68 positive cells are localized in human ovaries primarily to the vascular connective tissue and theca-lutein areas of the corpus luteum, although some are found in the granulose-lutein cell layer [11]. After ischemia reperfusion, impaired ovarian tissue melatonin effect was characterized by vascular injury and inflammation and the prevention of CD31 and CD68 markers.

\section{Material and Method}

The permission for the animal tests and experiments was given by the Animal Ethical Board of Dicle University Medical Faculty. Dicle University's Experimental Animal Laboratory Institute supplied 24 healthy adult female Wistar rats, weighing between 180 and $210 \mathrm{~g}$. The rats were selected according to their estrous cycle. The rats were housed in plastic rat cages at $26^{\circ} \mathrm{C} \pm 2^{\circ} \mathrm{C}$ and they were exposed to $10-12 \mathrm{~h}$ of day light. Animals were fed a standard laboratory diet and tap water ad libitum. A total of 24 Wistar rats were divided into four groups The rats were first numbered randomly and then randomly divided into 4 equal groups: sham, torsion, detorsion and melatonin groups In group I $(n=6)$ sham, In group II ovary torsion was not performed and no drug was administered. In group III h of ischemia and $2 \mathrm{~h}$ of reperfusion were performed and no drug was given. In group IV, Melatonin was dissolved in $1 \%$ ethanol just before use. Melatonin was injected $1 \mathrm{~h}$ before torsion to the torsion plus melatonin group. Each rat was administered intramuscular ketamine hydrochloride ( $50 \mathrm{mg} / \mathrm{kg}$ ketamine hydroxide) and xylazine hydrochloride (10 mg/kg Rompun, Bayer Istanbul, Turkey) for anesthesia. The rats, except for in the sham-operated group, were subjected to right unilateral adnexial torsion which induced ischemia by occlusion of the tuba-ovarian vessels for $2 \mathrm{hr}$. Rats in sham group were subjected to laparatomy only. In the torsion group, ovaries were surgically removed after $2 \mathrm{hr}$ of torsion. Right ovaries were surgically removed in all groups. The ovarian tissues were fixed in $10 \%$ neutral buffered formalin solution for 24 hours, dehydrated, cleared, and embedded in paraffin as usual. Serial tissue sections at a thickness of 4 - $5 \mu \mathrm{m}$ were cut using the microtome and stained with hematoxylin and eosin (H\&E) and Trichrom masson.

\subsection{Immunohistochemistry}

Formaldehyde-fixed tissue was embedded in paraffin wax for further immunohistochemical examination. Sections 
were deparaffinized in absolute alcohol. Endogenous peroxidase activity was blocked with absolute methanol containing $0.4 \%$ hydrochloric acid $(1 \mathrm{M})$ and $0.5 \%$ hydrogen peroxide (100 volumes) for 40 min at room After washing in water followed by $0.05 \mathrm{M}$ Tris-buffered saline, the sections were incubated in $1 \%$ trypsin. After washing in cold water, staining was carried out as above, using Ki67 (clone MIB1, Dako, 1/100) and CD68 as primary antibodies, slides were incubated with ultra V-block and subsequently either with PECAM-1 (CD31) primary antibody used at a dilution of 1/100. A biotinylated secondary antibody was applied for one hour. Slides were then exposed to streptovidin peroxidase and chromogen. After each treatment, the slides were washed in PBS. The slides, having been counter stained with Mayer's haematoxylin.

\subsection{Statistical Analysis}

Statistical analysis was performed using commercially available soft ware (SPSS v. 10.0, SPSS Inc., Chicago, IL, USA).The difference between the groups for non-parametric data with the Kruskal-Wallis test, two group comparisons Bonferonn correction was made after using the Mann-Whitney U test.

\section{Result}

All of these parameters were observed to be significantly decreased $(\mathrm{p}<0.05)$ in the ovariectomized group compared to the control group (Table 1).

The morphologic characteristics of the ovary tissues were normal in the control group. The ovaries from sham operation group were normal in histopathological appearance. Histological examination of ovaries after ischemia showed diffuse hemorrhage. The histopathologic appearance of apoptotic cells was characterized by the presence of pyknotic nucleus, and vacuolar appearance of the cells Melatonin treated group, the dilation of blood vessels and hemorrhage was observed slight granular appearance was near normal in cells and stromal cells. Structural integrity was achieved significantly ovary. In another section of the same group, the positive reaction in the small blood vessels in the stromal region of CD31 expression was observed. Preantral and antral follicles in the control group were surrounded with a network of blood vessels within the theca layer. Endothelial cells in these vessels were stained with CD31 (PECAM-I) (Figures 1-3).

Ischemia and ischemia reperfusion group ; Immunohistochemical labeling of anti-CD68 antibody, which is a specific for monocytes and macrophages, revealed the presence of macrophages infiltrating arround the stromal vessels and the granulosa cells in follicles that had histomorphologic characteristics of degeneration. The follicles and interfolicular area infiltrated with CD68 positive cells were increased in a time of ischemia-reperfusion exposure dependent manner.

\section{Discussion}

Ovarian torsion occurs due to the rotation of the adnexa. The degree of rotation and duration of torsion determine the severity of the injury [12]. Some authors concluded that ischemic-necrotic appearance of adnexa was the result of ovarian engorgement secondary to venous stasis, which did not produce a complete arterial

\begin{tabular}{ccc} 
Table 1. Comparisons of MDA value in groups. \\
\hline Comparisons MDAof group & Tissue p value & Plazma p value \\
\hline Group 1 - 2 & 0.001 & 0.001 \\
Group 1 - 3 & 0.001 & 0.001 \\
Group 1 - 4 & 0.001 & 0.001 \\
Group 1 - 5 & 0.001 & 0.001 \\
Group 2 - 3 & 0.001 & 0.001 \\
Group 2 - 4 & 0.001 & 0.001 \\
Group 2 - 5 & 0.001 & 0.001 \\
Group 3 - 4 & 0.001 & 0.001 \\
Group 3 - 5 & 0.001 & 0.001 \\
Group 4 - 5 & 0.001 & 0.001 \\
\hline
\end{tabular}




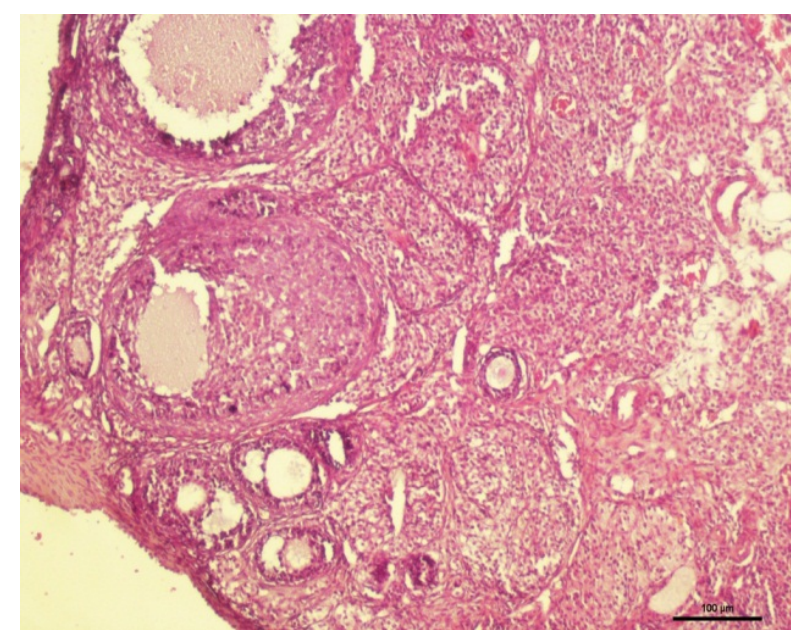

(a)

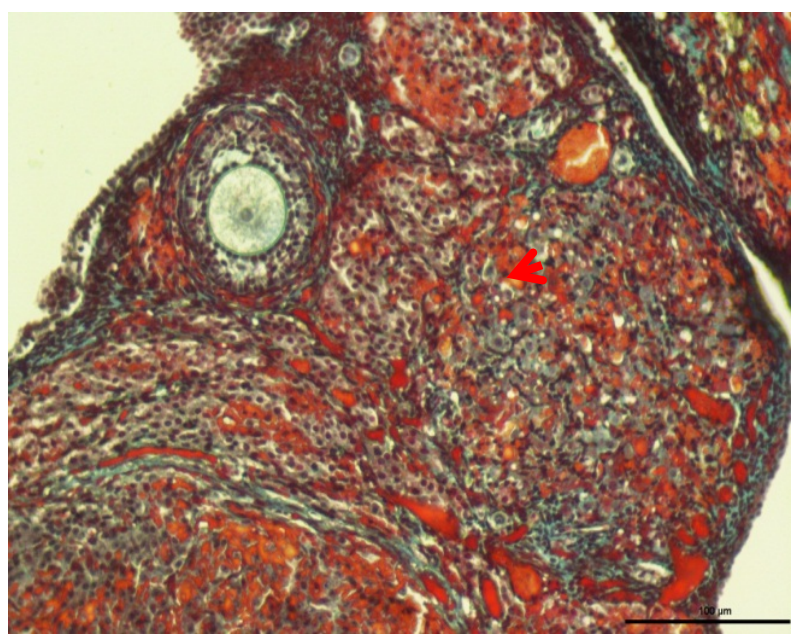

(c)

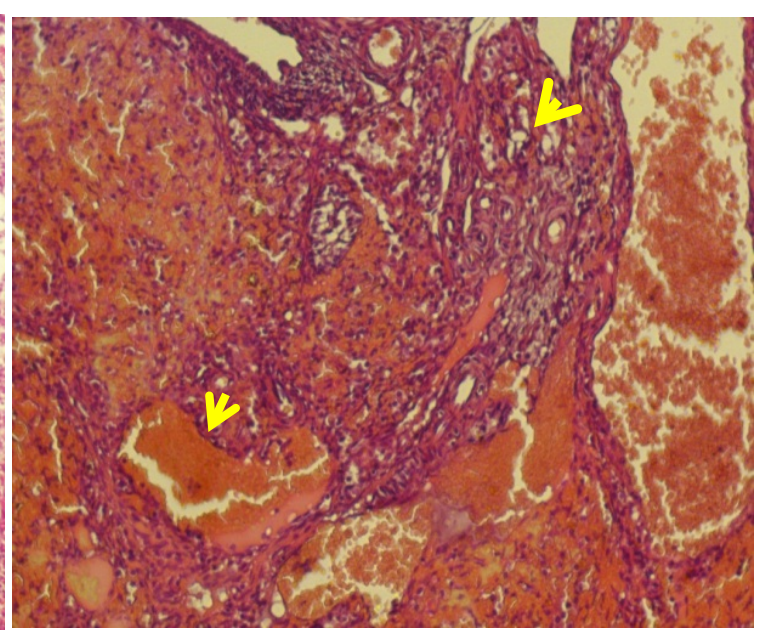

(b)

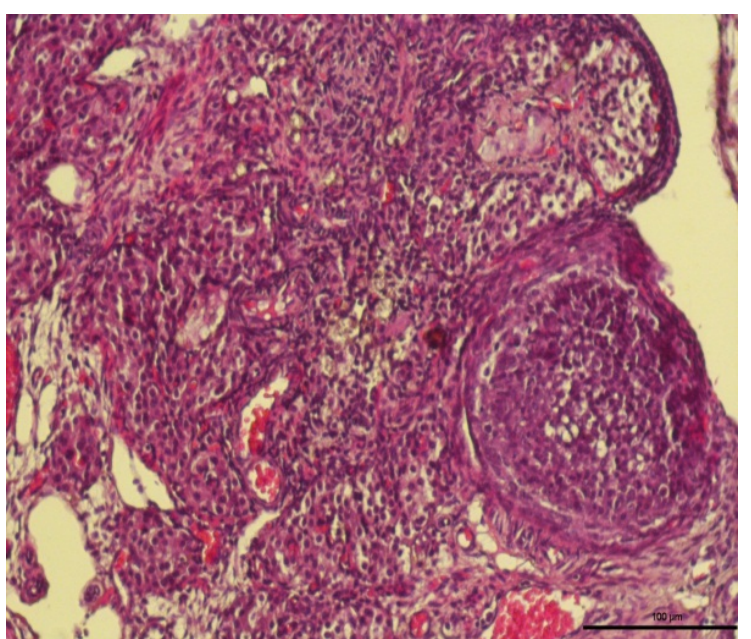

(d)

Figure 1. (a) Sham group Normal appreance of ovarian tissue, H-E staning Bar $100 \mu \mathrm{m}$; (b) Ischemia group Several follicles demonstrated coagulation necrosis, and the granulosa and luteinic cells showed vacuolar degeneration (yellow arrow) H-E staning Bar $100 \mu \mathrm{m}$; (c) Ischemia-reperfusion group, Follicular between vessels congestion, increased stromal tissue fibrosis and degeneration of follicular cells. Trichrom-Masson staning Bar $100 \mu \mathrm{m}$; (d) Significant decrease in the dilation of blood vessels and hemorhagie in the follicular cells of the structure in the regular disposition, H-E staning Bar $100 \mu \mathrm{m}$.

obstruction in most cases [13] [14]. Ovarian tissue contains angiogenic factors that stimulate endothelial cell migration [15] [16]. In the present study, vascular congestion, hemorrhage, inflammatory cell infiltration, and follicular cell degeneration were detected in the ovaries in the torsion group. The histopathological changes such as vascular congestion, edema, hemorrhage, and follicular degeneration were found to be decreased in the melatonin + torsion/detorsion group. According to our findings, melatonin seems to reduce the I/R damage due to ovarian torsion. The possible mechanisms for the protective effect of melatonin were vascular dilatation and hemorrhagie.

Melatonin is a powerful antioxidant with an influence on the endogenous antioxidant system. Concurrently, melatonin administration decreases lipid peroxidation and increases the levels of antioxidants [17]. MDA is a secondary product of oxidative stress formed during lipid peroxidation and is significantly increased by ischemia-reperfusion injury. Our studies, the levels of ovarian MDA were increased by ischemia-reperfusion injury.

PECAM-1 immunoreactivity was stronger in the endothelium of blood vessels, the corpus luteum, and the stroma in the hyperstimulated group than that in the control group.

Macrophages are able to regulate cellular proliferation, differentiation and apoptosis, as well as influence steroid 


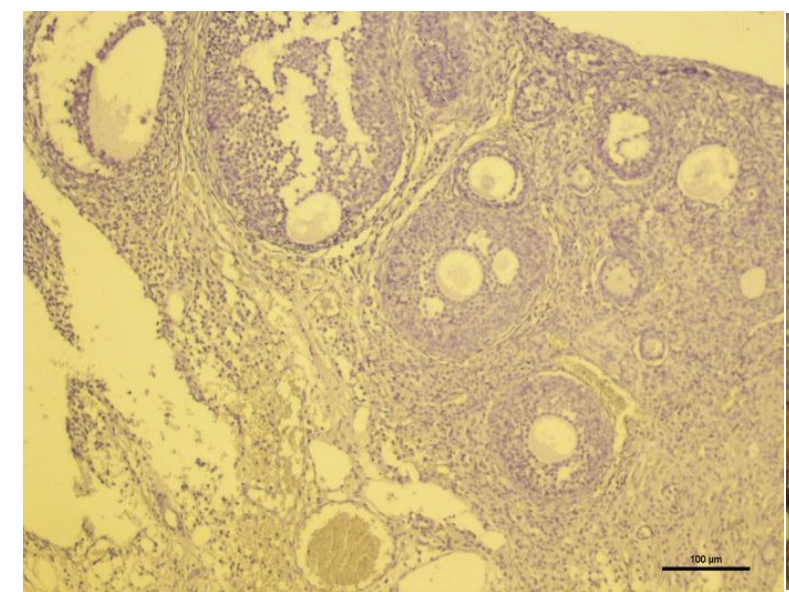

(a)

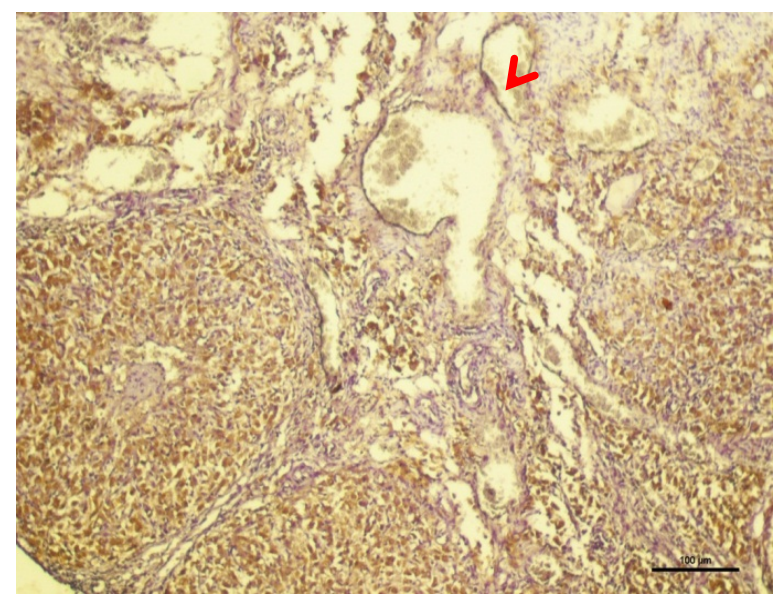

(a)

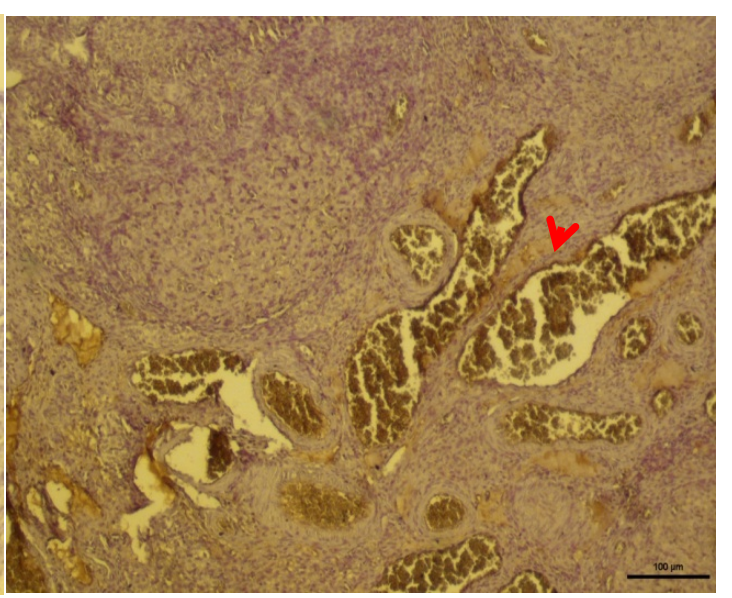

(b)

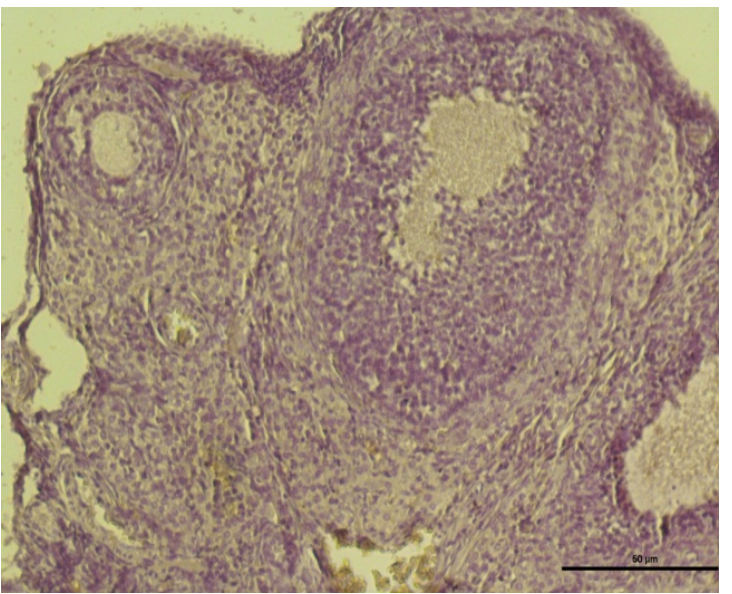

(b)

Figure 2. (a) Control group Preantral and antral follicles in the control group were surrounded with a network of blood vessels within the theca layer. PECAM-I immuno-staining Bar $100 \mu \mathrm{m}$; (b) Ischemia group Endothelial cells in the expanded vessel wall, the positive expression of PECAM-1 PECAM-I immuno-staining Bar $50 \mu m$; (c) Ischemiareperfusion group: PECAM-I expression is positive in vessel of the stromal area (red arrow), PECAM-I immuno-staining Bar $100 \mu \mathrm{m}$; (d) Ischemia-reperfusion + Melatonin group, CD31 positive expression in small vessels in the stromal area PECAM-I immuno-staining Bar $100 \mu \mathrm{m}$.

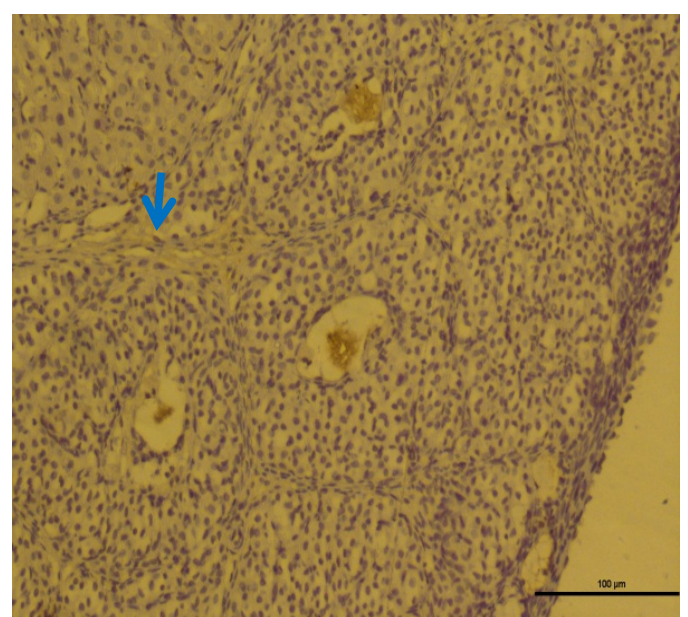

(a)

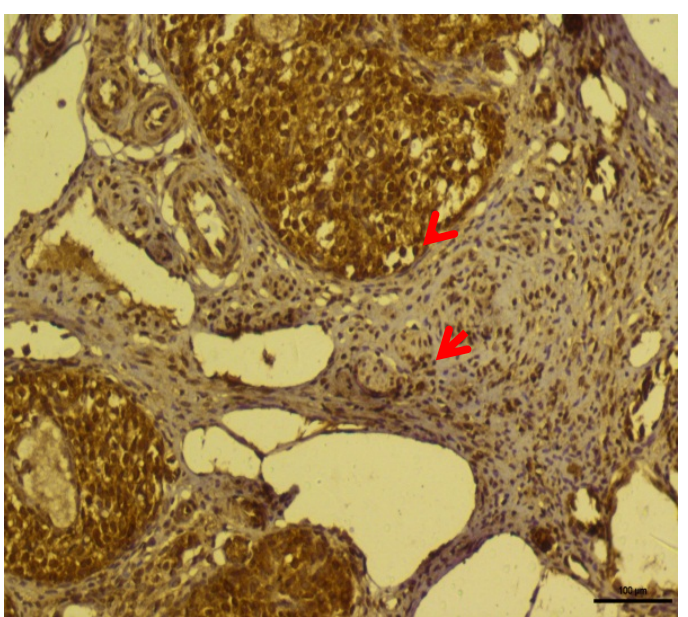

(b) 


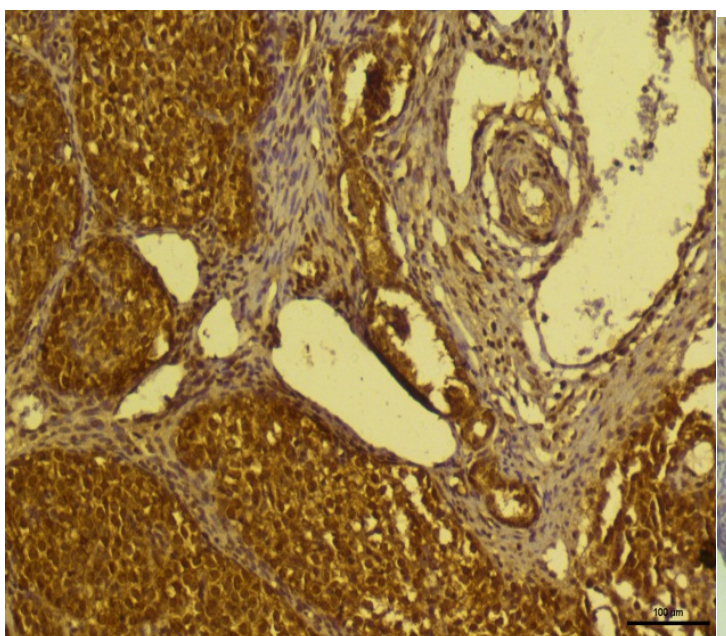

(c)

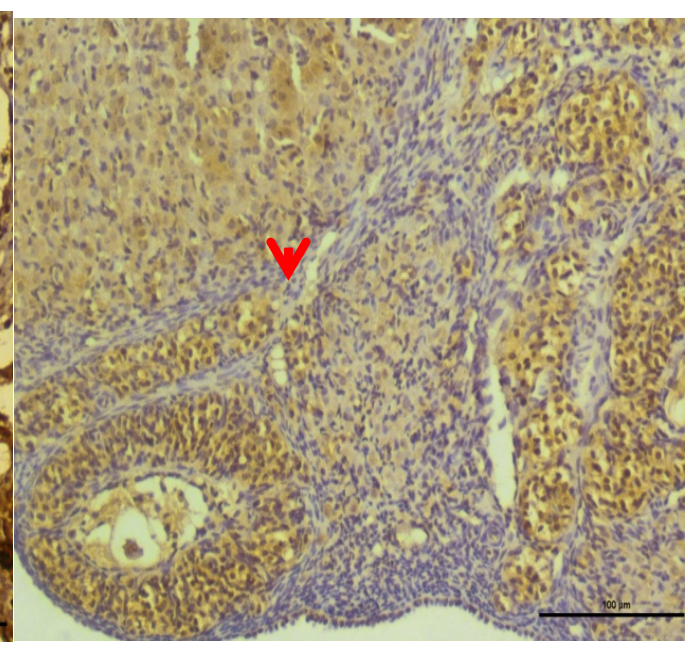

(d)

Figure 3. (a) Sham group, macrophage cells in interfollicular areas and weak CD68 expression, CD68 immun staining Bar $100 \mu \mathrm{m}$; (b) Ischemia group Follicles and interfolicular area with infiltrated macrophages positively immunolabeled with anti-CD68 antibody (red arrow). CD68 immun staining Bar $100 \mu \mathrm{m}$; (c) Ischemiareperfusion group around blood vessels in stromal areas, positive CD68 expression in granular cells, CD68 immun staining Bar $100 \mu \mathrm{m}$; (d) Ischemia-reperfusion + Melatonin group, Depending on the reduction of macrophage activity, follicular and stromal area weak CD68 expression. Bar $100 \mu \mathrm{m}$.

production, vascularization and tissue remodelling during follicle growth, ovulation and luteinization. It is important to consider that the marker used to identify macrophages reveals specific information about the changing functional characteristics of the cells; for instance, in the rabbit, luteolysis is associated with an initial increase in scavenger receptor positive macrophages followed by recruitment of CD68 positive macrophages [18]. In our study, in ischemia and ischemia reperfusion group, the expression of CD68 follicles of granular cells, and stromal vascular cells in the corpus luteum around has been shown to be positively marked. Melatonin after ischemia reperfusion CD68 expression is weak, due to the reduction of the inflammatory effects and hemorrhage is thought that melatonin is effective. Macrophage cell proliferation and apoptosis are important tools of follicular development, regulating the balance between angiogenesis.

\section{References}

[1] Halici, Z., Karaca, M., Keles, O.N., Borekci, B., Odabasoglu, F., Suleyman, H., et al. (2008) Protective Effects of Amlodipine on Ischemia-Reperfusion Injury of rat Ovary: Biochemical and Histopathologic Evaluation. Fertility and Sterility, 90, 2408-2415. http://dx.doi.org/10.1016/j.fertnstert.2007.10.007

[2] Kara, M., Daglioglu, Y.K., Kuyucu, Y., Tuli, A. and Tap, A. (2012) The Effect of Edaravone on Ischemia-Reperfusion Injury in Rat Ovary. European Journal of Obstetrics \& Gynecology and Reproductive Biology, 162, 197-202. http://dx.doi.org/10.1016/j.ejogrb.2012.02.026

[3] Abramov, A.Y., Scorziello, A. and Duchen, M.R. (2007) Three Distinct Mechanisms Generate Oxygen Free Radicals in Neurons and Contribute to Cell Death during Anoxia and Reoxygenation. The Journal of Neuroscience, 27, 11291138. http://dx.doi.org/10.1523/JNEUROSCI.4468-06.2007

[4] Li, R.M. (2002) Jackson Reactive Species Mechanisms of Cellular Hypoxia-Reoxygenation Injury. American Journal of Physiology—Cell Physiology, 282, 227-241. http://dx.doi.org/10.1152/ajpcell.00112.2001

[5] Oelsner, G. and Shashar, D. (2006) Adnexial Torsion. Clinical Obstetrics and Gynecology, 40, 459-463. http://dx.doi.org/10.1097/00003081-200609000-00006

[6] Oelsner, G., Cohen, S.B., Soriano, D., Adman, D., Mashiach, S. and Carp, H. (2003) Minimal Surgery for the Twisted Ischemic Adnexa Can Preserve Ovarian Function. Human Reproduction, 18, 2599-2602. http://dx.doi.org/10.1093/humrep/deg498

[7] Tan, D.X., Chen, L.D., Poeggeller, B., et al. (1993) Melatonin: A Potent Endogenous Hydroxyl Radical Scavenger. Endocrine Journal, 1, 57-60.

[8] Allegra, M., Reiter, R.J., Tan, D.X., et al. (2003) The Chemistry of Melatonin’s Interaction with Reactive Species. 
Journal of Pineal Research, 34, 1-10. http://dx.doi.org/10.1034/j.1600-079X.2003.02112.x

[9] Leica Biosystems, the Pathology Compony PECAM1 (CD31) Antibody. http://www.leicabiosystems.com/...antibodies/.../cd31

[10] Wu, R.J., Van der Hoek, K.H., Ryan, N.K., Norman, R.J. and Robker, R.L. (2004) Macrophage Contributions to Ovarian Function. Human Reproduction, 10, 119-133. http://dx.doi.org/10.1093/humupd/dmh011

[11] Gaytan, F., Morales, C., Garcia-Pardo, L., Reymundo, C., Bellido, C. and Sanchez-Criado, J.E. (1998) Macrophages, Cell Proliferation, and Cell Death in the Human Menstrual Corpus Luteum. Biology of Reproduction, 59, 417-425.

[12] Inderdeo, D.S., Edwards, D.R., Han, V.K. and Khokha, R. (1996) Temporal and Spatial Expression of Tissue Inhibitors of Metalloproteinases during the Natural Ovulatory Cycle of the Mouse. Biology of Reproduction, 55, 498-508.

[13] Olsner, G., Bider, D. and Goldenberg, M. (1993) Long Term Follow-Up of Twisted Ischemic Adnexa Managed by Detorsion. Fertility and Sterility, 60, 976-979.

[14] Gordon, J.D., Hopkins, K.L., Jeffrey, R.B. and Guidice, L.C. (1994) Adnexal Torsion: Color Doppler Diagnosis and Laparoscopic Treatment. Fertility and Sterility, 61, 383-385.

[15] Nisolle, M., Casanas-Roux, F., Qu, J., Motta, P. and Donnez, J. (2000) Histologic and Ultrastructural Evaluation of Fresh and Frozen-Thawed Human Ovarian Xenografts in Nude Mice. Fertility and Sterility, 74, 122-129. http://dx.doi.org/10.1016/S0015-0282(00)00548-3

[16] Weissman, A., Gotlieb, L., Colgan, T., Jurisicova, A., Greenblatt, E.M. and Casper, R.F. (1999) Preliminary Experience with Subcutaneous Human Ovarian Cortex Transplantation in the NOD-SCID Mouse. Biology of Reproduction, 60, 1462-1467. http://dx.doi.org/10.1095/biolreprod60.6.1462

[17] Liu, Y., Shimizu, I., Omoya, T., Ito, S., Gu, X.S. and Zuo, J. (2002) Protective Effect of Estradiol on Hepatocytic Oxidative Damage. World Journal of Gastroenterology, 8, 363-366.

[18] Krusche, C.A., Vloet, T.D., Herrler, A., Black, S. and Beier, H.M. (2002) Functional and Structural Regression of the Rabbit Corpus Luteum Is Associated with Altered Luteal İmmune Cell Phenotypes and Cytokine Expression Patterns. Histochemistry and Cell Biology, 118, 479-489. 